\title{
Talking Heads, Italo Calvino, and the Surface of Things: An Essay in Pieces Daniel P. Gunn
}

EARLY IN Stop Making Sense, Jonathan Demme's 1984 film of a Talking Heads concert, the camera films three musicians as they dance slowly forward and backward during a song. Intent on their instruments, shivering with their heads down, they move back and forth in front of the camera at different rates of speed, crossing and recrossing arhythmically, on separate planes of motion, like pistons in a slow motion engine. The camera lingers for a moment or two over this image from its position slightly behind and to the side of the musicians, playing with the motion on the stage, seeing what the audience cannot see. Watching this for the first time, three years ago, I thought: these are the bodies of words; I am watching the way words move.

Seen from the right angle, words are dense and supple material, present, in any sentence, like the flesh. And they move: they yawn and stretch with athletic grace; they move backward and forward at different rates of speed; they roll and tumble and collide; their cries echo and reverberate in the gymnasium of words, in the particle chamber of words. As a responsible reader, intent on the serious business of language, its ideological and cultural work, I pretend that words are mere ghosts, fleshless and transparent when held to the light. But I cannot always maintain this pretense. After all, even a responsible reader has some interests which refuse to become entwined with words like ideology, class, overdetermined, and structure, and which persist, in spite of every effort at renunciation, with the stubborn intensity of desire.

Two sentences, from Henry Fielding's Tom Jones:

Twelve Times did the iron Register of Time beat on the sonorous Bell-metal, summoning the Ghosts to rise, and walk their nightly 
Round. - In plainer Language, it was Twelve o'Clock, and all the Family, as we have said, lay buried in Drink and Sleep, except only Mrs. Western, who was deeply engaged in reading a political Pamphlet, and except our Heroine, who now softly stole down Stairs, and having unbarred and unlocked one of the House Doors, sallied forth, and hastened to the Place of Appointment. (Book X, chapter 9)

In the first sentence, Fielding is clearly writing like someone else-like a bombastic dramatist, say, perhaps even like Shakespeare - and we are not meant to take his borrowed language seriously. It is parody, or, more precisely, burlesque: a joke. But in this sentence, as so often in Fielding, we are nevertheless invited to take pleasure in the language, to indulge ourselves in it, even as we recognize it for what it is. If we respond to this invitation, something curious happens: once the words reveal themselves, they stop functioning in the ordinary way, and we become aware of their density and material reality. Even as we read, we see that the words are just words, after all, and we enjoy their artful disposition in the pattern of the sentence, their absurd and wonderful sonority: the iron Register of Time, the nightly Round of the ghosts. This curious kind of awareness leaks over into the next sentence, too, when we encounter our Heroine and softly stole down Stairs, sallied forth and the Place of Appointment. These are playful, flirtatious phrases, drawn from the romance or the adventure story, and they reverberate gently against the language of the first sentence. Can we take them seriously, after what has just occurred? Perhaps, perhaps not: the words are just waking into self-consciousness, just yawning and stretching; they are mildly aware of themselves as words.

Here is another sentence, this time from Mr. Palomar, by Italo Calvino, translated by William Weaver:

Now his gaze, giving the landscape a fickle glance, will linger on the breast with special consideration, but will quickly include it in an impulse of good will and gratitude for the whole, for the sun and the sky, for the bent pines and the dune and the beach and the rocks and the clouds and the seaweed, for the cosmos that rotates around those haloed cusps. (1.1.2) 
Here it is not parody but syntax that calls our attention to the play of language. As Mr. Palomar's "impulse of good will and gratitude" moves outward, the sentence expands into a series of lists: first two nouns, then six, then a noun and a subordinate clause recapitulating the whole and drawing the sentence back to its center. These lists (and particularly the second one) give Calvino the opportunity to linger, himself, over words: bent pines, dune, beach, rocks, clouds, seaweed. The sentence takes on the character of a chant or a litany, some kind of hypnotic ritual: one noun succeeds another, each preceded by "and" and the definite article, and we linger over each with loving attention, as Mr. Palomar lingers over the breast. Originally a description of something happening in Mr. Palomar's consciousness, the sentence transforms itself into a beautiful and self-sufficient list of nouns, conscious only of its own rhythm, expanding toward the cosmos, with everything else shrinking away in the distance, until the last image of "those haloed cusps" calls us back into the real world of the narrative. For a moment, words are not merely windows into ideas or descriptions; they cloud up; they assert their own reality, their heaviness and texture; they draw our attention themselves, for their own sake.

When, in an uncharacteristically lyrical moment, the priggish questioning voice of the "Ithaca" section of Ulysses asks "What in water did Bloom, waterlover, drawer of water, watercarrier, returning to the range, admire?" the answering voice replies with a long list, part of which reads as follows:

... its indisputable hegemony extending in square leagues over all the region below the subequatorial tropic of Capricorn: the multisecular stability of its primeval basin: its luteofulvous bed: its capacity to dissolve and hold in solution all soluble substances including millions of tons of the most precious metals: its slow erosions of peninsulas and islands, its persistent formation of homothetic islands, peninsulas and downwardtending promontories: its alluvial deposits: its weight and volume and density: its imperturbability in lagoons, atolls, highland tarns: its gradation of colours in the torrid and temperate and frigid zones: its vehicular ramifications in continental lakecontained streams and confluent oceanflowing rivers with their tributaries and transoceanic currents, gulfstream, north and 
south equatorial courses: its violence in seaquakes, waterspouts, Artesian wells, eruptions, torrents, eddies, freshets, spates, groundswells, watersheds, waterpartings, geysers, cataracts, whirlpools, maelstroms, inundations, deluges, cloudbursts: its vast circumterrestrial ahorizontal curve . . (17.193-208)

The pleasure of reading, in a passage like this one, comes largely from the sensuous and tactile feel of the words as they roll off the tongue or reverberate in the auditory imagination, syllable by syllable: luteofulvous, ramifications, circumterrestrial, subequatorial. We are also conscious, as we read, of the richness and verbal ingenuity of the writing, in the long list of violent phenomena, say, or the conspicuous use of imperturbability or violence to maintain the syntactical parallel, and of the comprehensiveness and internal consistency of the language, the way it fills out the form and touches every conceivable base. This is hyper-consciousness, reading to the second power: we see how the words work at the very moment they are working on us. There is literal sense, of course - otherwise we would not be able to recognize features like ingenuity or comprehensiveness-but making sense seems no longer the principal business of language in this passage. Here, as in the other passages I have quoted, what we are conscious of is not meaning, but the material which produces meaning. And we get lost in this material, as we read, watching the play of language. Sense shrinks away in the distance, and the word detaches itself, all surface, heavy, solid, opaque.

But this is the most ordinary thing in the world, perhaps, for an experienced reader of prose: to see words as words, to pause and admire the graceful contours of a sentence. Just last summer, for example, reading Marilynne Robinson's Housekeeping, I found myself stopping constantly to respond to the dizzying appeal of the writing, in sentences like this one:

Her net would sweep the turning world unremarked as a wind in the grass, and when she began to pull it in, perhaps in a pell-mell ascension of formal gentlemen and thin pigs and old women and odd socks that would astonish this lower world, she would gather the net, so easily, until the very burden itself lay all in a heap just under the surface. 
To admire a sentence like this one, however, to see it as language, I must step back and cease reading. There is none of the dazed inward tendency we have seen in the first three examples; there is no sense here that the language is somehow seeing itself, or enclosing itself in quotation marks. My consciousness of the artfulness of the language, then, remains somehow separate from my consciousness of the sentence's meaning; it is an intellectual distraction, an aside, something that happens in literature class or in a moment of reverie. What makes the passages from Fielding, Calvino, and Joyce unusual, I think, is the way they incorporate an awareness of the material reality of language into the very process of construing the sentence. To read these passages attentively is necessarily to recognize the density and artificiality of the language. In fact, at one level, such recognition is what these sentences are about. Marilynne Robinson's sentences, meanwhile, are about Fingerbone and Sylvie and Ruth, about birds nesting in the attic, about this train sliding off a railroad bridge into the water, gracefully, as if in slow motion.

Because the language of the first three passages I quoted invites awareness of its linguistic character - seems even to be aware of itself-it is possible to speak of it as "self-conscious," and I am going to use that term to describe it. But the effect I am concerned with here is distinct from the characteristic technique of what is ordinarily called "self-conscious" fiction-Laurence Sterne's Tristram Shandy, for example, or Cervantes' Don Quixote. Such fiction, which, as Robert Alter writes in Partial Magic: The Novel as a Self-Conscious Genre (Berkeley, 1975), "flaunts its own condition of artifice" and "probes into the problematic relationship between real-seeming artifice and reality," usually does so overtly, either by making direct references to reading and writing, the material reality of language, and the false and arbitrary character of narrative representation, or by making symbolic or metaphoric references (using mirrors, artists, doubles, and the like) which have the same effect. These references may remind us of the material reality of words, but they are not themselves instances of language aware of its own heaviness and opacity, as in the three examples we have been considering. In standard self-conscious references (Don Quixote and Sancho discussing the novel in which they appear, for example, or Tristram complaining that he is living faster than he can write), a meta-language is created to call attention to the fictional enterprise, including its lan- 
guage-but the meta-language itself is used in an unproblematical and transparent way; it makes sense, communicating to us about the language of fiction, without putting up any resistance or becoming involved with itself. The peculiar effect of self-consciousness I have been considering in Fielding and Joyce and Calvino occurs as a reflex incorporated into the very language of fiction; as the words turn in on themselves and call attention to their artificial character, they constitute their own meta-language, by implication rather than direct statement.

Sometimes, then, language congeals and thickens as we read; it calls attention to its own artificiality, its dense material texture as a medium of expression. The ordinary production of meaning is suspended, for a moment, at least, and we are left with the words in their pure state, in some zone antecedent to convention and interpretation. They are in the condition of the frozen words Pantagruel throws like rocks onto the ship's deck in Rabelais: hin, hin, his, tick, tock, crack, brededin, brededac, frr, frrr (Book 4, chapter 56). And as we watch, these words shiver and grow, right there on the deck. They balloon to gigantic proportions, like the playful letter $A$ which invades a man's house and torments him in an old Eastern European cartoon. We might clamber over these words now, we think, they are so huge. Or we might jump from sentence to sentence, like Nabokov's Gradus, "swinging down to the foot of the page from line to line as from branch to branch," now and then "hiding between two words." (See Pale Fire, note to line 17.)

When self-conscious language reveals itself, I feel a pleasure at once aesthetic and intellectual; it is as if some mysterious and ecstatic lyrical energy has been released. This occurs, I think, because of the rich material presence of the word, sensuous and pleasurable in itself, and also because of an implied threat against ordinary meaning. A moment of self-consciousness diminishes ordinary meaning, makes it seem small and thin, a lie we have been living all these years. There is almost a sense of danger, a thrill: the list might go on forever, the sentence might never re-emerge from parody, we might never flicker back into ordinary and unproblematic reading. All of this comes in a sudden and momentary flash of awareness, a rush of blood to the face, and then it is gone. 
In Calvino's novel, Mr. Palomar looks down from his terrace on the city, trying to see it as he imagines the birds see it - that is, as if "this rise and fall of roofs, old tiles and new" were "the true crust of the earth . . . uneven but compact, even if furrowed by gaps whose depth cannot be known, chasms or pits or craters":

Separated by irregular and jagged gulfs of emptiness, proletarian terraces with lines for drying laundry and with tomato plants growing in tin cans directly face residential terraces with espaliered plants growing against wooden trellises, garden furniture of white-painted cast iron, awnings; pealing campaniles; facades of public buildings, in profile and full-face; garrets and penthouses, illegal and unpunished constructions; pipe scaffoldings of constructions in progress or left half finished; large windows with curtains, and little WC windows; ocher walls and burnt-sienna walls, walls the color of mold from whose crevices clumps of weeds spill their pendulous foliage; elevator shafts; towers with double and triple mullioned windows; spires of churches with madonnas; statues of horses and chariots; great mansions that have decayed into hovels, hovels restructured into smart bachelor apartments; and domes that make round outlines against the sky in every direction and at every distance, as if to confirm the female, Junoesque essence of the city: white domes or pink or violet, according to the hour and the light, veined with nervatures, crowned by lanterns surmounted by other, smaller domes. (2.1.1)

These "domes that make round outlines" and "confirm the female, Junoesque essence of the city" may remind us of the breast in the previous passage-and the repetition of the image emphasizes the continuity of $\mathrm{Mr}$. Palomar's meditation, the persistence of his character as an observer. More important here, though, is the image of the richness and variety of the surface, its dense texture. Part of Mr. Palomar's meditative enterprise seems to be to force himself to attend to the surface of things - not to see through things, as he habitually does, but to linger over the "panorama of the surface," which is "already so vast and rich and various that it more than suffices to saturate the mind." This is a built-in insight, I think, about reading Calvino's prose: as the sentences unwind, often in long, luxuriant 
lists, of meats, birds, trees, names, or in rich syntactical patterns, we are invited to adopt the same attitude that Mr. Palomar adopts toward the world, by attending to the play of language, which, in a sentence, constitutes the rich and various surface of things. Such reading is an effort to imagine or build up the material reality of the surface, to see it as a dense and uneven crust rather than a transparent window into the meaning which lies below, to see it as possessing weight.

Reading on the surface, we are aware of the presence of language, of its shimmering and numinous beauty, which pushes all other considerations into the background. This accounts for the feelings of mingled exhilaration and longing that writing like Calvino's is likely to produce. It is impossible for me not to feel that this desire in the presence of the pure word is part of some more comprehensive longing, for the ideal, for some mystery at the boundary of consciousness. Plato explained the mystery which attaches itself to even the simplest wave of erotic longing, in a corridor or a public square, by postulating that the sexes were once united in a single ideal form. Erotic desire is the desire to regain that original state; it is our awareness of that original state, which we cannot apprehend with ordinary consciousness or the senses. In the same way, a moment in the absolute presence of language is shrouded in mystery: the wave of excitement is a mode of apprehending the ideal.

Self-conscious language draws us thus into the presence of words, releasing their exuberant, lyrical play. How odd that the scientific and technical discourse of "Ithaca" should be lyrical - that it should strike us as somehow beautiful - but it does strike us that way, because we are in a position to watch the motion of words, to listen to their strange echoes and reverberations.

American popular culture is always on the verge of unintentional parody, at best just this side of a collapse into the purely conventional and banal. In Stop Making Sense, Demme and Talking Heads take this condition and make it a positive virtue, a built-in feature of the discourse of concert and film, so that everything is parodic or half-parodic, and consciously so, and nothing can be taken seriously. Here, as in Joyce, there are no purely straight passages; there are only various levels of posturing. But, again as 
in Joyce, the discourse will not cohere as a parody, either; it is too random and nihilistic in its undermining, and we are not allowed to dismiss one criticized discourse in favor of another. Everything is consciously artificial and produced (and reproduced), and, in this sea of fragments, we lose our illusion of some coherent meaning for the images beneath the surface, and we are left only with the surface, the aesthetic images themselves, seen as images. But as in our verbal examples, this turns out not to be a loss: there is finally the buoyant play of the images, the motion of words, the ecstatic dance of the sign freed momentarily from the labor of signification.

When David Byrne performs "Psycho Killer" accompanied by a small portable tape player at the beginning of Stop Making Sense, it is a warning, at the beginning of a film dominated by sound, that sound on film is not natural, not real, but shaped and determined by a conventional aesthetic and technical system. It is a step outside of the cultural code of the concert, which usually presents the illusion that these human beings are producing these sounds, right now, spontaneously, naturally, in this clear and understandable way. Byrne places himself on the level of the tape player, as a symbol, a word, as that which is not natural.

As the film and show progress, Demme and Talking Heads extend and reinforce this initial image by pointedly exposing the technical processes of concert production and film making-laying bare the technique of both production and reproduction. The concert stage, for example - the principal image at any rock concert and the visual center of the film-is assembled out of pieces and fragments before our eyes. At first, we are confronted with junky backstage chaos, all red brick and stepladders, white block letters on the wall, piles of nondescript equipment here and there, with only Byrne present at the center of the stage, in a white suit. One by one, over the course of the first six songs, the other members of the band attach themselves to Byrne, each with an attendant penumbra of machinery and amplifiers, filling out and deepening the central image of the concert: bass guitar, drums, guitar, synthesizer, more drums, back-up singers, more speakers and amplifiers. During this period of construction and manipulation, and throughout the entire film, for that matter, the members of the production crew make no effort to disguise their presence; they move nonchalantly around the stage, adjusting speakers, carrying 
lights and cameras and instruments, dollying pieces of the set from here to there. Finally, when a screen is lowered in front of what remains of the backstage clutter (colors and split-screen images are projected onto it later), we realize that the assembly is complete, and we are looking at a glossy, high-tech set, at a band, at a rock concert.

But the fragments never really coalesce in the ordinary way, because, as Michael Sragow wrote in the Boston Phoenix, Talking Heads "seem to be testing just how many musical influences a group can incorporate without losing its own cutting edge" ("Once in a Lifetime," October 30, 1984). The members of the band don't seem to belong together on the same stage. The bass player, in fishnet stockings and go-go boots; the teeshirted and wonderfully kinetic backup singers; the Latin-influenced rhythm section; the stoned-out guitarist; the drummer, a refugee from some suburban tavern band: they are all echoes, parodic references to other musical styles and cultural scenes, and they insist on their fragmentary identities. Byrne himself is a chameleon, equally resistant to interpretation-part revival singer, part athlete, part crazed automaton, in a nervous dance. Throughout the film, these visual and musical elements persistently resist our attempts to make a coherent whole out of them; they remain images, consciously artificial, creatures of the surface.

In the substance of their show, Talking Heads complement the selfconscious production by consistently stressing their own artificiality, by refusing to allow themselves to become "natural." The members of the band hardly talk at all during the show, except for the degenerate chatter during the parodic "Tom-Tom Club" segment - which is to say, they do not talk in their own voices. The songs themselves intentionally sever the connections between gesture and the sense of a lyric, or between segments of a song; the lyrics are chanted, fragmented, surreal, just on the edge of meaning, and the music consists either of parodies of discrete styles or of repeated electronic and synthesized motifs, inhuman and impersonal. And the images on stage during the show, like those at the beginning, are often disquieting and bizarre. During one song, for example, detached pictures flash on a screen behind the stage - a house, a bookshelf against a whitewashed wall, parts of the human body. A floor lamp stands at the front of the stage, near the microphones. Images that we might feel comfortable 
with are jammed into unfamiliar contexts, so that their artificiality and unhominess can be exposed, so that we will see them as images, first and last, and stop being so comfortable with them. Late in the film, Byrne walks out in a huge version of the white suit (someone gets credit for "building" it), a monstrosity which dwarfs his head and hands. But he acts as if nothing is wrong: there is nothing unusual about this, he seems to say; there is nothing unusual at all about the big suit.

The images in the Talking Heads show are thus arbitrary and surreal, often consciously weird; they resist interpretation, threaten and jam it, and attempt to remain on the surface, pure language, like words in a sentence by Fielding or Calvino or Joyce. In the film, this resistance is tinged with desperation: it is part of an uneasy response to the burden of modern consciousness, our sense that any public self must be, in Carter Ratcliff's words, a "Frankenstein self, a monster put together from bits and pieces of image tissue" ("David Byrne and the Modern Self," Artforum, May, 1985). The real threat, Ratcliff and Talking Heads suggest, is not the condition of fragmentation, but what threatens to disguise that condition: "a world of institutions, 'lifestyles,' and scenes designed to absorb the self" into seamless patterns which pretend to make sense. In the light of such a threat, fragmentation and nihilism gather an ethical dimension; the surface of language provides us with a last vestige of authenticity, a last home for the crazed and insistent dance of the human spirit. If, as Michael Sragow says, this film celebrates "human elasticity and resilience," it does so by celebrating the elasticity and resilience of language, its capacity for resistance even in the face of the "dehumanizing violence," "anomie," and "mechanization" of modern culture. At home on the surface of language, Talking Heads play in the interstices of meaning, according to a guerrilla rhythm of avoidance, like a saxophone player snaking around all the conventional lines and phrases without becoming identified with any of them.

Self-consciousness about the artificial character of the language and resistance to ordinary meaning: these are allied phenomena, in prose narrative and in film. In Stop Making Sense, they produce a tremendous lyrical energy, the visual equivalent of the play of language. Watching this film, we know we are watching a show, and it is impossible not to be swept up in the play of the images and gestures and words, the sheer euphoric feel of 
visual and musical languages, even as we see them for what they are. The beauty of the film, its aesthetic quality, has nothing to do with ordinary definitions of lyricism or grace; like the felicities of "Ithaca," it is a product of self-consciousness and the motion of words.

Let me conclude with one more small fragment, from another film, Woody Allen's The Purple Rose of Cairo. A film character escapes into the real world, where his attractions and limitations are exposed: he has lots of money, but it is fake; he is a good kisser, but he doesn't know what happens after the fade; in short, he is endearingly faithful, naive, and courageous, but somehow cold and inflexible, not as good as the genuine article. At the end of the film, there is a moment which has something like the same effect as the passages I quoted at the beginning of this essay. Mia Farrow sits in a movie theater watching Fred Astaire and Ginger Rogers dance across the screen. There she is, at the movies, watching images; here we are, watching her. Her face is pale and luminous, barely freckled, framed by the grainy darkness of the theater and lit by flickering gray and white light from the screen. Eventually, the image begins to fade, slowly, and the film seems to be over, but this is only a dark moment on the screen, and the picture returns for a brief self-conscious reprise before the credits come up. Why does it move me so, this reflex of the medium, this brief play of light on a screen? Perhaps because, like the pure word, the last image knows itself. It is present on its own terms, eerie and consciously artificial, at once as resonant and as graceful as a gesture by Fred Astaire. 